\title{
The Anti-Inflammatory Activity of HMGB1 A Box Is Enhanced When Fused with C-Terminal Acidic Tail
}

\author{
Wei Gong, ${ }^{1}$ Yingru Zheng, ${ }^{2}$ Fan Chao, ${ }^{1}$ Yuan Li, ${ }^{1}$ Zhizhen Xu, ${ }^{1}$ Gang Huang, ${ }^{1}$ Xiang Gao, ${ }^{3}$ \\ Song $\mathrm{Li}^{3}$ and Fengtian $\mathrm{He}^{1}$ \\ ${ }^{1}$ Department of Biochemistry and Molecular Biology, College of Basic Medical Sciences, Third Military Medical University, \\ Chongqing 400038, China \\ ${ }^{2}$ Department of Obstetrics and Gynecology, Research Institute of Surgery, Daping Hospital, Third Military Medical University, \\ Chongqing 400042, China \\ ${ }^{3}$ Center for Pharmacogenetics, Department of Pharmaceutical Sciences, School of Pharmacy, University of Pittsburgh, Pittsburgh, \\ PA 15261, USA
}

Correspondence should be addressed to Fengtian He, hefengtian06@yahoo.com.cn

Received 8 August 2009; Revised 28 November 2009; Accepted 28 January 2010

Academic Editor: Rudi Beyaert

Copyright $\odot 2010$ Wei Gong et al. This is an open access article distributed under the Creative Commons Attribution License, which permits unrestricted use, distribution, and reproduction in any medium, provided the original work is properly cited.

\begin{abstract}
HMGB1, composed of the A box, B box, and C tail domains, is a critical proinflammatory cytokine involved in diverse inflammatory diseases. The B box mediates proinflammatory activity, while the A box alone acts as a specific antagonist of HMGB1. The $\mathrm{C}$ tail contributes to the spatial structure of A box and regulates HMGB1 DNA binding specificity. It is unknown whether the $\mathrm{C}$ tail can enhance the anti-inflammatory effect of A box. In this study, we generated fusion proteins consisting of the A box and C tail, in which the B box was deleted and the A box and C tail were linked either directly or by the flexible linker sequence $\left(\mathrm{Gly}_{4} \mathrm{Ser}_{3}\right.$. In vitro and in vivo experiments showed that the two fusion proteins had a higher anti-inflammatory activity compared to the $\mathrm{A}$ box alone. This suggests that the fused $\mathrm{C}$ tail enhances the anti-inflammatory effect of the A box.
\end{abstract}

\section{Introduction}

High-mobility group box 1 (HMGB1) is an important nonhistone nuclear protein [1], but can also be released from the nucleus into the extracellular space, acting as a critical proinflammatory cytokine in response to exogenous bacterial products or endogenous inflammatory stimuli $[2,3]$. Although originally defined as a late mediator of endotoxin lethality $[2,4]$, a recent report showed that HMGB1 was elevated within six hours of traumatic injury in humans, suggesting that it may be integral to the early inflammatory response to trauma [5]. HMGB1 simulates the downstream proinflammatory cascade responses by binding to three receptors: Toll-like receptor 4 (TLR4), TLR2, and receptor for advanced glycation end products (RAGE) [6]. Because of its pivotal role in inflammatory pathogenesis as a late and early proinflammatory cytokine, HMGB1 has become an attractive target for the clinical management of sepsis and certain infectious and inflammatory disorders $[7,8]$.
HMGB1 is highly conserved across species and is wildly distributed in eukaryotic cells from yeast to human [9]. Human HMGB1, a 215-amino acid protein, contains three major functional domains: the $\mathrm{A}$ box, the $\mathrm{B}$ box, and the C-terminal acidic tail (C tail) $[10,11]$. Structurefunction analyses reveal that the proinflammatory cytokineinducing capacity of HMGB1 localizes to the B box, with the most significant cytokine functionality mapping in the first 20 amino acid residues of this domain [12]. However, the A box alone can competitively inhibit the binding of HMGB1 to its receptors and attenuate the proinflammatory effect of the full length HMGB1 and the B box peptide. The A box is thus considered a specific antagonist of HMGB1 [13, 14]. Moreover, recent reports showed that the $\mathrm{C}$ tail contributed to the spatial structure of both A box and B box and regulated HMGB1 DNA binding specificity $[11,15]$. However, it is unknown whether the $\mathrm{C}$ tail can enhance the anti-inflammatory activity of the A box. 
The aim of this study was to identify whether the antiinflammatory activity of the A box could be enhanced by a fused $\mathrm{C}$ tail. We generated two fusion proteins consisting of the A box and C tail, in which the B box was deleted and the $\mathrm{A}$ box and $\mathrm{C}$ tail were linked either directly or through the flexible linker sequence, $\left(\mathrm{Gly}_{4} \mathrm{Ser}\right)_{3}$. In vitro and in vivo experiments demonstrated that the two fusion proteins, especially the $\left(\mathrm{Gly}_{4} \mathrm{Ser}\right)_{3}$ linked protein, had a higher anti-inflammatory activity compared to the A box alone, indicating that the fused $\mathrm{C}$ tail enhances the anti-inflammatory effect of the A box. The fusion proteins composed of the A box and $\mathrm{C}$ tail may have more potential clinical significance for the treatment of HMGB1-associated inflammatory diseases.

\section{Materials and Methods}

2.1. Preparation of Recombinant Human HMGB1 (rHMGB1), rHMGB1 A Box (A Box), and Control Protein Dihydrofolate Reductase (DHFR). The three proteins were expressed in Escherichia coli (E. coli) DH5 $\alpha$ with a pQE-80L prokaryotic expression vector (Qiagen, Germany) containing an Nterminal $6 \times$ His tag-encoding sequence. The proteins were purified using a $\mathrm{Ni}^{2+}$-nitrilotriacetic acid $\left(\mathrm{Ni}^{2+}{ }^{2} \mathrm{NTA}\right)$ chromatography kit (Qiagen, Germany) as previously described [16]. Judging from SDS-PAGE gel results, the purity of the three proteins was greater than $90 \%$.

2.2. Cloning, Expression and Purification of the Two Fusion Proteins Composed of the A Box and C Tail. The recombinant proteins corresponding to the full-length human HMGB1 A box fused with $\mathrm{C}$ tail directly (A box $+\mathrm{C}$ tail) and the $\mathrm{A}$ box fused with C tail by a $\left(\mathrm{Gly}_{4} \mathrm{Ser}\right)_{3}$ linker $\left(\mathrm{A}\right.$ box $+\left(\mathrm{Gly}_{4} \mathrm{Ser}\right)_{3}+\mathrm{C}$ tail) are depicted in Figure 1. The $\mathrm{A}$ box $+\mathrm{C}$ tail protein was constructed by one-step opposite direction PCR (TaKaRa MutanBest Kit, Japan) according to the manufacturer's instructions and using the oligonucleotides $5^{\prime}$-GAAGAGGAGGAAGATGAGGAAGAT- $3^{\prime}$ (forward primer) and $5^{\prime}$ TGTCTCCCCTTTGGGAGGGATATA-3' (reverse primer) and a full-length human HMGB1 cDNA cloned in pUC19 vector as a template. The resulting plasmid containing the A box $+C$ tail encoding fragment was named pUC19/A box $+\mathrm{C}$ tail. The fragment encoding the $\mathrm{A} \mathrm{box}+\left(\mathrm{Gly}_{4} \mathrm{Ser}\right)_{3}+\mathrm{C}$ tail protein was constructed by three rounds of one-step opposite direction PCR. For the first round of one-step opposite direction PCR, the forward primer 5'-GGCGGAGGTGGATCAGAAGAGGAGGAAGATGAG- $3^{\prime}$ and the reverse primer $5^{\prime}$-TGTCTCCCCTTTGGGAGGGATATA$3^{\prime}$ were used to amplify the plasmid pUC19/A box $+\mathrm{C}$ tail. The resulting plasmid containing the A box $+\mathrm{Gly}_{4} \mathrm{Ser}+\mathrm{C}$ tailencoding sequence was named pUC19/A box $+\mathrm{Gly}_{4} \mathrm{Ser}+\mathrm{C}$ tail. Similarly, the second and the third rounds of one-step opposite direction PCR were done with the primers $5^{\prime}$ GGAGGAGGCGGTTCGGGCGGAGGTGGATCAGAAGAG-3' (forward primer) and 5'-TGTCTCCCCTTTGGGAGGGATATA-3' (reverse primer) (for the second round of
PCR), and the primers $5^{\prime}$-GGCGGAGGTGGATCTGGAGGAGGCGGTTCGGGCGGA-3' (forward primer) and 5' TGTCTCCCCTTTGGGAGGGATATA-3' (reverse primer) (for the third round of PCR). Following the third round of one-step opposite direction PCR, the plasmid containing the A box $+\left(\mathrm{Gly}_{4} \mathrm{Ser}\right)_{3}+\mathrm{C}$ tail-encoding sequence was generated and named pUC19/A box $+\left(\mathrm{Gly}_{4} \mathrm{Ser}\right)_{3}+\mathrm{C}$ tail. After sequencing, the fragments encoding the $\mathrm{A}$ box $+\mathrm{C}$ tail and A box $+\left(\mathrm{Gly}_{4} \mathrm{Ser}\right)_{3}+\mathrm{C}$ tail proteins were excised from plasmids pUC19/A box $+\mathrm{C}$ tail and pUC19/A box $+\left(\mathrm{Gly}_{4} \mathrm{Ser}\right)_{3}+\mathrm{C}$ tail, respectively, and were individually ligated into the KpnI/HindIII cloning site of a pQE-80L prokaryotic expression vector. The two expression vectors were then individually transformed into E. coli $\mathrm{DH} 5 \alpha$ and induced by isopropyl $\beta$-D-1-thiogalactopyranoside (IPTG, Sigma, USA) to express the corresponding proteins. Expression was verified by western blot analysis using a mouse antihuman HMGB1 monoclonal antibody (Abnova, Taiwan) directed against the A box. The expressed recombinant fusion proteins were purified by the $\mathrm{Ni}^{2+}$-NTA chromatography kit under normal condition and following the instructions of the manufacturer. The purities of the proteins were analyzed by SDS-PAGE.

2.3. Endotoxin Removal from Proteins. Endotoxin was removed from all of the protein samples used in this study, including rHMGB1, A box, DHFR, A box $+\mathrm{C}$ tail, and A box $+\left(\mathrm{Gly}_{4} \mathrm{Ser}\right)_{3}+\mathrm{C}$ tail, by polymyxin B columns (Pierce, USA) according to the manufacturer's instructions. The LPS content in the recombinant proteins was measured by the chromogenic Limulus amebocyte lysate assay (BioWhittaker, USA).

2.4. Cell Culture. THP-1 cells (American Type Culture Collection) were cultured in RPMI 1640 medium (Gibco, USA) supplemented with $10 \%$ fetal bovine serum (Gibco, USA), penicillin $(100 \mathrm{U} / \mathrm{mL})$, and streptomycin $(100 \mu \mathrm{g} / \mathrm{mL})$ (Gibco, USA) in a $37^{\circ} \mathrm{C}$ humidified incubator with $5 \% \mathrm{CO}_{2}$ and $95 \%$ room air. For stimulation experiments, polymyxin $B$ was added to the cell culture medium at 6 units of polymyxin B per pg of LPS. The amount of polymyxin B used was sufficient to neutralize the remaining amount of contaminating endotoxin [13].

2.5. Measurement of TNF- $\alpha$ and IL-6. TNF- $\alpha$ and IL-6 levels were determined by enzyme-linked immunosorbent assay (ELISA) kits (R\&D System, USA) according to the instructions of the manufacturer. The concentrations of the two cytokines were calculated with reference to standard curves of purified recombinant TNF- $\alpha$ and IL- 6 at various dilutions.

2.6. Animal Experiments. Male BALB/c mice (20-22 g) were purchased from the Laboratory Animal Center of The Third Military Medical University. The mice were housed under standard temperature, light and dark cycles, and manipulated according to the local conventions for the care and use of laboratory animals (Chongqing, China). 


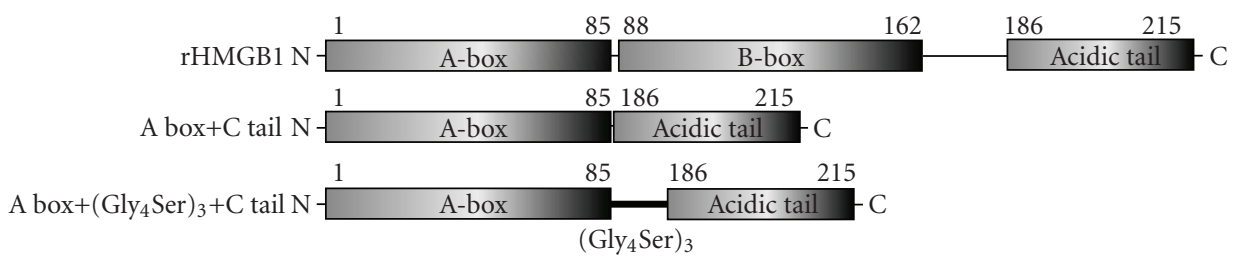

FIGURE 1: Schematic representation of the C tail-fused A box proteins used in this work. Wild type human HMGB1 is composed of three domains: the A box (amino acid residues 1-85), the B box (amino acid residues 88-162), and the C tail (amino acid residues 186-215). A box $+\mathrm{C}$ tail: $\mathrm{A}$ box fused with $\mathrm{C}$ tail directly. $\mathrm{A}$ box $+\left(\mathrm{Gly}_{4} \mathrm{Ser}\right)_{3}+\mathrm{C}$ tail: $\mathrm{A}$ box fused with $\mathrm{C}$ tail via a $\left(\mathrm{Gly}{ }_{4} \text { Ser }\right)_{3}$ linker.

2.7. Serum Collection. BALB/c mice were injected i.p. with $\mathrm{LD}_{75}$ doses of $15 \mathrm{mg} / \mathrm{kg}$ LPS (Sigma, USA) as previously described [12] and were treated at 0 and 12 hours after LPS injection with A box, A box $+\mathrm{C}$ tail, $\mathrm{A}$ box $+\left(\mathrm{Gly}_{4} \mathrm{Ser}\right)_{3}+\mathrm{C}$ tail, or DHFR control proteins (40 nmol/mouse i.p.). The sera of the mice were collected through orbital bleeding 6, 12 and 18 hours after LPS injection, respectively.

2.8. LPS Lethality. BALB/c mice, subjected to an $\mathrm{LD}_{75}$ doses of LPS as above, were treated at 0 and 12 hours after LPS administration with A box, A box $+\mathrm{C}$ tail, A box $+\left(\mathrm{Gly}_{4} \mathrm{Ser}\right)_{3}+\mathrm{C}$ tail, or DHFR control proteins ( $40 \mathrm{nmol} /$ mouse i.p.). Mortality was monitored for up to 10 days after the procedure to ensure no late death occurred.

2.9. Statistical Analysis. Data are presented as means \pm standard deviation. Statistical analysis was performed with the SPSS13.0 software. Differences in TNF- $\alpha$ and IL-6 levels between treatment groups were determined by one-way ANOVA. Survival rates were analyzed by the Kaplan-Meier method with comparisons between different groups. A $P$ value less than .05 was considered statistically significant.

\section{Results}

3.1. Preparation of Recombinant Proteins. The fusion proteins A box $+\mathrm{C}$ tail and $\mathrm{A}$ box $+\left(\mathrm{Gly}_{4} \mathrm{Ser}\right)_{3}+\mathrm{C}$ tail were successfully constructed and expressed in E. coli DH5 $\alpha$ by IPTG induction, and expression was confirmed by western blot (Figure 2(a)). The two proteins were purified by $\mathrm{Ni}^{2+}$-NTA chromatography, and their purities were greater than $90 \%$ as judged by SDS-PAGE (Figure 2(b)). After endotoxin was removed by polymyxin B columns, the LPS content in rHMGB1, A box, DHFR, A box $+\mathrm{C}$ tail and $\mathrm{A}$ box $+\left(\mathrm{Gly}_{4} \mathrm{Ser}\right)_{3}+\mathrm{C}$ tail was $1.09 \mathrm{ng} / \mathrm{mL}, 1.08 \mathrm{ng} / \mathrm{mL}$, $1.54 \mathrm{ng} / \mathrm{mL}, 1.06 \mathrm{ng} / \mathrm{mL}$, and $1.17 \mathrm{ng} / \mathrm{mL}$, respectively.

\subsection{The C Tail-Fused A Box Proteins Inhibited HMGB1-} Induced TNF- $\alpha$ and IL-6 Release In Vitro More Efficiently than A Box Alone. The levels of proinflammatory cytokines TNF$\alpha$ and IL- 6 in THP- 1 cell culture supernatant were measured 6 hours after rHMGB1 administration in the presence of A box $+\mathrm{C}$ tail, A box $+\left(\mathrm{Gly}_{4} \mathrm{Ser}\right)_{3}+\mathrm{C}$ tail, A box or DHFR control proteins. As shown in Figures 3(a) and 3(b), A box, A box $+\mathrm{C}$ tail, and $\mathrm{A}$ box $+\left(\mathrm{Gly}_{4} \mathrm{Ser}\right)_{3}+\mathrm{C}$ tail inhibited HMGB1-induced TNF- $\alpha$ and IL- 6 release from THP- 1 cells.

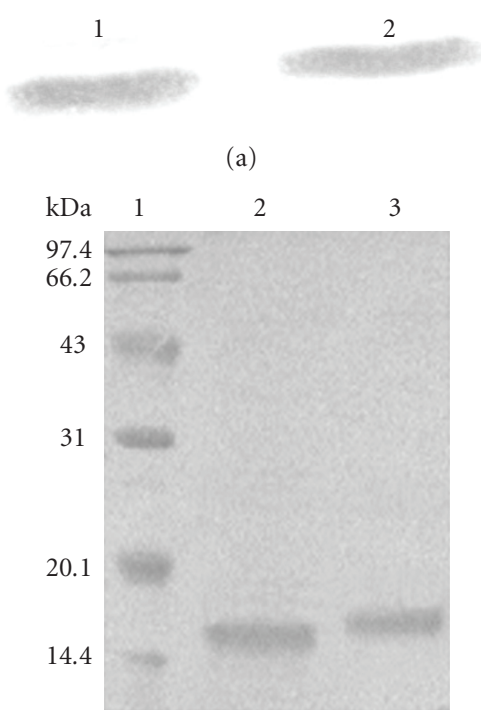

(b)

FIGURE 2: Western blot and SDS-PAGE analysis of the C tailfused A box proteins. (a) Identification of the two fusion proteins expressed in E. coli $\mathrm{DH} 5 \alpha$ by western blot using a mouse antihuman HMGB1 monoclonal antibody directed against A box. Lane 1:A box $+\mathrm{C}$ tail; Lane 2:A box $+\left(\mathrm{Gly}_{4} \mathrm{Ser}\right)_{3}+\mathrm{C}$ tail. (b) Purity analysis of the two fusion proteins by SDS-PAGE. After purification by $\mathrm{Ni}^{2+}$-NTA chromatography, the purities of the two fusion proteins were analyzed with SDS-PAGE. Equal amounts of purity proteins $(10 \mu \mathrm{g})$ were loaded in Figure 2(b), separated by $12 \%$ PAGE gel electrophoresis. Lane 1:Molecular weight standards; Lane 2:A box $+\mathrm{C}$ tail; Lane 3:A box $+\left(\mathrm{Gly}_{4} \mathrm{Ser}\right)_{3}+\mathrm{C}$ tail.

The two $\mathrm{C}$ tail-fused A box proteins were more efficient than A box alone, and the A box $+\left(\mathrm{Gly}_{4} \mathrm{Ser}\right)_{3}+\mathrm{C}$ tail had the highest activity. These results indicated that the $\mathrm{C}$ tail-fused A box proteins, especially A box $+\left(\mathrm{Gly}_{4} \mathrm{Ser}\right)_{3}+\mathrm{C}$ tail, had an enhanced antiinflammatory effect in vitro.

3.3. The C Tail-Fused A Box Proteins Had a Higher AntiInflammatory Activity In Vivo Compared to A Box Alone. TNF- $\alpha$ and IL- 6 levels in the sera of the mice subjected to endotoxemia were assayed by ELISA at 6,12 , and 18 hours after treatment with $\mathrm{A}$ box, A box $+\mathrm{C}$ tail, $\mathrm{A}$ box $+\left(\mathrm{Gly}_{4} \mathrm{Ser}\right)_{3}+\mathrm{C}$ or DHFR control proteins. As shown in Figures 3(c) and 3(d), the A box and the two C tail-fused A 


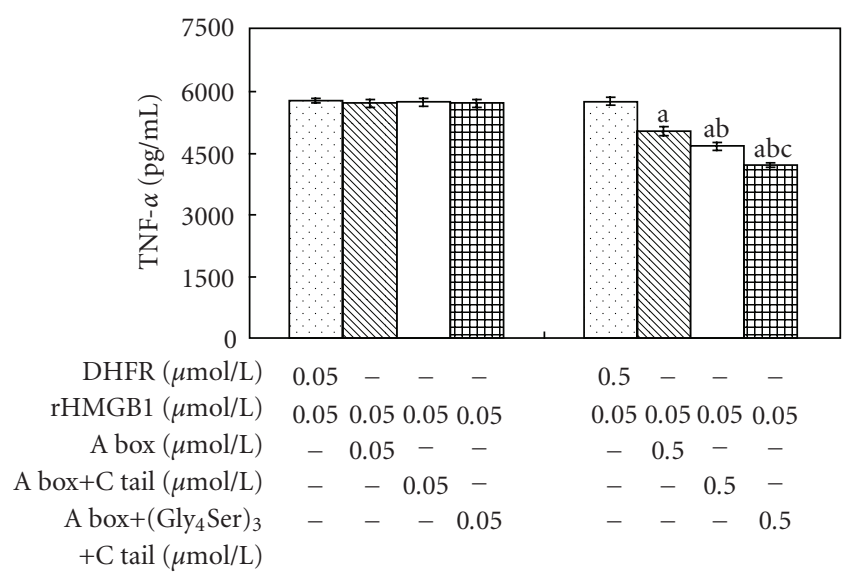

(a)

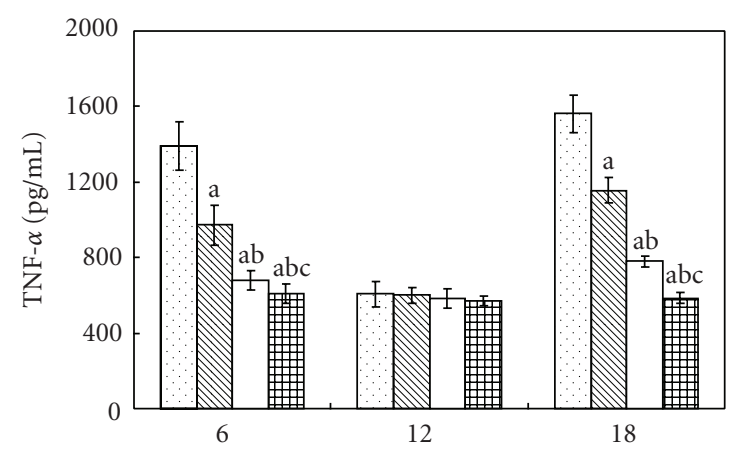

(h)

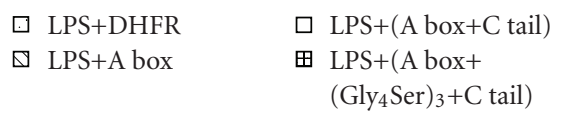

(c)

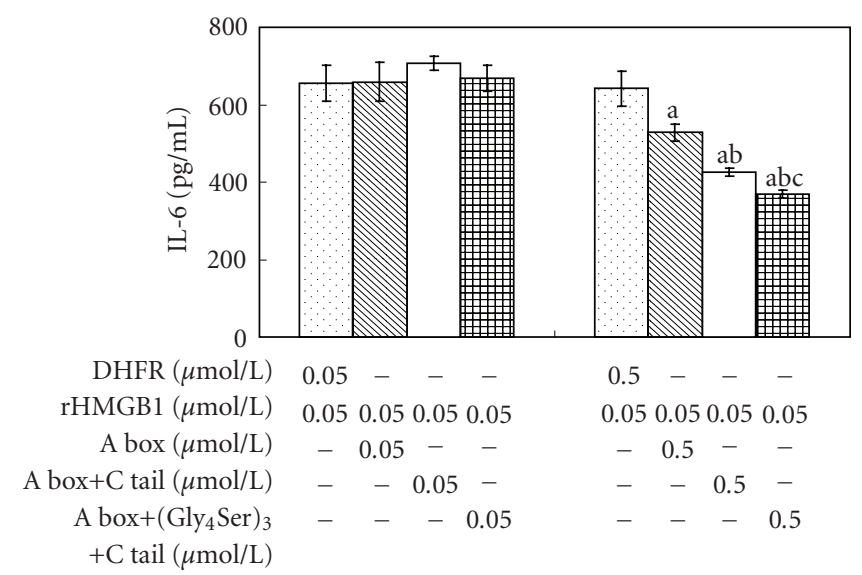

(b)

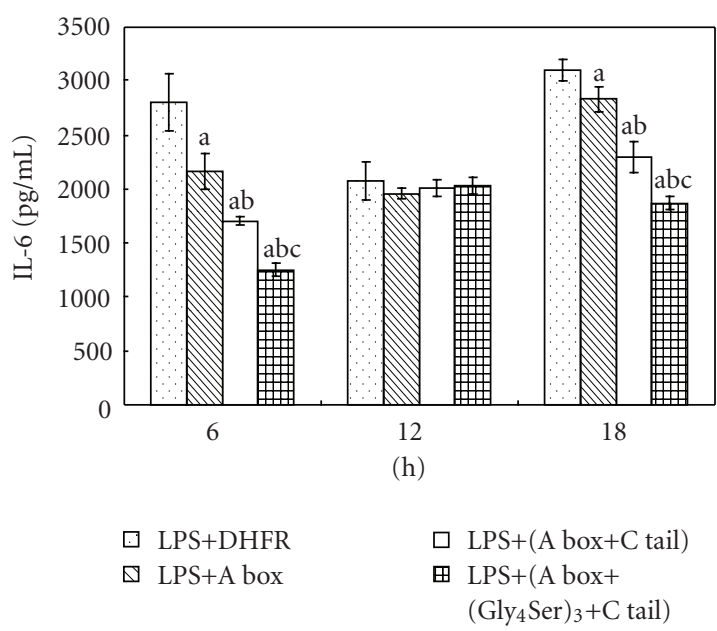

(d)

FIgure 3: The C tail-fused A box could suppress TNF- $\alpha$ and IL-6 release in vitro and in vivo more efficiently than A box alone. (a) and (b) The $\mathrm{C}$ tail-fused A box could inhibit HMGB1-induced TNF- $\alpha$ and IL- 6 release in vitro more efficiently than A box alone. THP-1 cells in 96-well plates were treated with $\mathrm{rHMGB} 1(0.05 \mu \mathrm{mol} / \mathrm{L})$ and various concentrations of A box, A box $+\mathrm{C}$ tail, $\mathrm{A}$ box $+\left(\mathrm{Gly}{ }_{4} \mathrm{Ser}\right)_{3}+\mathrm{C}$ tail, or DHFR control proteins (as indicated) for 6 hours in the presence of polymyxin B ( 6 units per pg of LPS). The levels of TNF- $\alpha$ and IL- 6 in the cultured supernatants were measured by ELISA. Each experiment was performed in triplicate and repeated three times. (c) and (d) The C tail-fused A box could reduce serum TNF- $\alpha$ and IL-6 levels in the mice subjected to endotoxemia more efficiently than A box alone. BALB/c mice ( 5 mice/group), subjected to $\mathrm{LD}_{75}$ doses of LPS $(15 \mathrm{mg} / \mathrm{kg})$, were treated at 0 and 12 hours after LPS injection with A box, A box $+\mathrm{C}$ tail, A box $+\left(\mathrm{Gly}_{4} \mathrm{Ser}\right)_{3}+\mathrm{C}$ tail or DHFR control proteins $(40 \mathrm{nmol}$ per mouse). The sera of the mice were obtained from orbital blood 6, 12 , and 18 hours after LPS injection respectively. The serum levels of TNF- $\alpha$ and IL- 6 were determined by ELISA. Each experiment was repeated three times. The results showed that the A box alone and the two $\mathrm{C}$ tail-fused A box proteins could significantly inhibit TNF- $\alpha$ and IL- 6 release in vitro and in vivo. The $\mathrm{A}$ box $+\left(\mathrm{Gly}_{4} \mathrm{Ser}\right)_{3}+\mathrm{C}$ tail fusion protein had the most efficient inhibitory activity, followed by the $\mathrm{A}$ box $+\mathrm{C}$ tail fusion protein and the A box. Data shown are the means \pm standard deviation and were analyzed with one-way ANOVA. a: $P<.05$ versus DHFR; b: $P<.05$ versus A box; c: $P<.05$ versus A box + C tail.

box proteins significantly reduced the serum TNF- $\alpha$ and IL6 levels in 6 and 18 hours. The potency of inhibitory activity was in the order of A box $+\left(\mathrm{Gly}_{4} \mathrm{Ser}\right)_{3}+\mathrm{C}$ tail, A box $+\mathrm{C}$ tail, and A box. But there were no inhibitory effects in 12 hours. Moreover, the LPS lethality assay showed that A box and the two C tail-fused A box proteins significantly prolonged life time and improved the survival rates of LPS-induced endotoxemia mice (Figure 4 ). The protective activity was in the same order as above. These results indicated that the $\mathrm{C}$ tail-fused A box proteins, especially A box $+\left(\mathrm{Gly}_{4} \mathrm{Ser}\right)_{3}+\mathrm{C}$ tail, had an enhanced anti-inflammatory effect in vivo.

\section{Discussion}

We have clearly demonstrated for the first time in this study that the in vitro and in vivo anti-inflammatory activity of HMGB1 A box was enhanced when fused with the $\mathrm{C}$ tail, and that the fusion protein containing a $\left(\mathrm{Gly}_{4} \mathrm{Ser}\right)_{3}$ linker had the most anti-inflammatory effect.

As a late and early proinflammatory cytokine, extracellular HMGB1 has been found to play a pivotal role in the pathogenesis of many acute and chronic inflammatory diseases by binding to three receptors: TLR4, TLR 2 and 


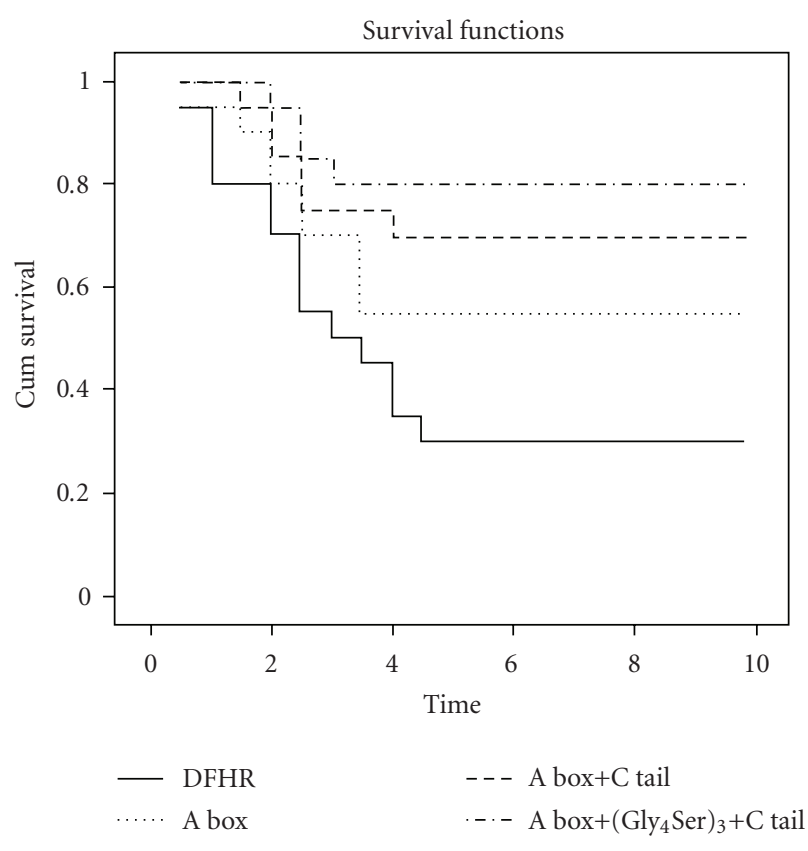

Figure 4: The C tail-fused A box could more effectively protect against endotoxin lethality. BALB/c mice (20 mice/group), subjected to $\mathrm{LD}_{75}$ doses of LPS, were treated at 0 and 12 hours after LPS administration with A box, A box $+\mathrm{C}$ tail, A box $+\left(\mathrm{Gly}_{4} \mathrm{Ser}\right)_{3}+\mathrm{C}$ tail, or DHFR control proteins ( $40 \mathrm{nmol} /$ mouse i.p.). Mortality was monitored for up to 10 days. The survival rates were analyzed by the Kaplan-Meier method with comparisons between different groups. The results showed that the A box alone and the two $\mathrm{C}$ tail-fused $\mathrm{A}$ box proteins could significantly prolong life time and improve the survival rates of the mice $(P<.05)$. The $\mathrm{A}$ box $+\left(\mathrm{Gly}_{4} \mathrm{Ser}\right)_{3}+\mathrm{C}$ tail protein had the most protective effect, followed by $\mathrm{A}$ box $+\mathrm{C}$ tail and A box $(P<.05)$.

RAGE [2, 6, 17, 18]. HMGB1 has a special structurefunctional characteristic in that the $\mathrm{B}$ box contains proinflammatory activity and the A box alone can attenuate the proinflammatory effect of the full length HMGB1 and the $\mathrm{B}$ box peptide. The $\mathrm{C}$ tail, consisting of 30 amino acid residues, is a continuous array of aspartic acid and glutamic acid residues. The phylogenetically conservative $\mathrm{C}$ tail suggests that it has a very important role in the biological activities of HMGB1 [11]. It has been reported that the $\mathrm{C}$ tail can contribute to the spatial structure of both the A box and B box, and can also regulate HMGB1 DNA binding specificity $[11,15]$. However, it is not clear whether the $\mathrm{C}$ tail can enhance the anti-inflammatory activity of the A box. To address this question, we generated two $\mathrm{C}$ tail-fused A box proteins, in which the B box was deleted and the A box was fused with $\mathrm{C}$ tail either directly or linked by a $\left(\mathrm{Gly}_{4} \mathrm{Ser}\right)_{3}$ sequence. The in vitro and in vivo anti-inflammatory assays demonstrated that the two novel fusion proteins could reduce proinflammatory cytokine (TNF- $\alpha$ and IL-6) release and protect against endotoxin lethality more effectively than A box alone, indicating that the $\mathrm{C}$ tail enhances the anti-inflammatory activity of $\mathrm{A}$ box.
$\left(\mathrm{Gly}_{4} \mathrm{Ser}\right)_{3}$ is a flexible linker that is commonly used in the construction of single-chain antibody fragments [19]. It can help form the spatial structure of domains on both sides without interfering with the function of the recombinant proteins, and can even contribute to the activity of the molecules. Our results showed that the $\mathrm{C}$ tail-fused $\mathrm{A}$ box protein containing the $\left(\mathrm{Gly}_{4} \mathrm{Ser}\right)_{3}$ linker had a higher anti-inflammatory activity than the protein fused directly, suggesting that the linker sequence might enhance the anti-inflammatory function of the fusion protein to some extent.

Macrophages and monocytes have a central role in coordinating responses to injury and infection. TNF- $\alpha$ is one of the earliest cytokines released by activated macrophages and plays an important role in the pathogenesis of inflammation and endotoxic shock. IL-6 is a very important monocytederived cytokine. HMGB1, a key proinflammatory factor, is nearly as potent as LPS in stimulating downstream cytokine synthesis in monocytes and macrophages. HMGB1 participates in "cross-talk" for the propagation and amplification of downstream proinflammatory cascade responses. TNF- $\alpha$ and IL-6 are two major HMGB1-stimulated cytokines [2, 20]. Thus, in this study, these two cytokines were measured to evaluate the anti-inflammatory activity of the HMGB1 fragment proteins.

The murine endotoxemia model is commonly used in researches of HMGB1 inflammatory activity [2, 13]. In this study, the LPS-induced mice endotoxemia model was established to evaluate the in vivo anti-inflammatory activity and the endotoxin lethality protective effect of the HMGB1 fragment proteins. Both LPS and HMGB1 bind TLR4 to stimulate downstream proinflammatory responses. Therefore, aside from competitively inhibiting the binding of HMGB1 to its receptors, the A box and C tail-fused A box proteins may exert their in vivo anti-inflammatory effect and LPS-lethality protective function by blocking the binding of LPS to TLR4.

Results from this study may have therapeutic implications. As a specific antagonist of HMGB1, the A box has recently been suggested to be a potential anti-inflammatory agent [13]. Our results showed that the fused $C$ tail could enhance the anti-inflammatory activity of the A box, which suggests that the $\mathrm{C}$ tail-fused A box proteins, especially the $\left(\text { Gly }{ }_{4} \text { Ser }\right)_{3}$-linked fusion protein, may have more potential clinical significance for the treatment of HMGB1-associated inflammatory diseases than the A box alone. More studies are required to uncover the molecular mechanism by which the fused $\mathrm{C}$ tail enhances the anti-inflammatory activity of $\mathrm{A}$ box.

\section{Acknowledgments}

This work was supported by the National Natural Science Foundation of China (no. 30670411 to F He), the Medical Science Research Project of the Eleventh Five-year Plan of PLA (06H027 to F. He), and the Natural Science Foundation of Chongqing (CSCT 2008BB5022 to F. He). W. Gong and Y. Zheng contributed equally to this work. 


\section{References}

[1] K. Javaherian, J. F. Liu, and J. C. Wang, "Nonhistone proteins HMG1 and HMG2 change the DNA helical structure," Science, vol. 199, no. 4335, pp. 1345-1346, 1978.

[2] H. Wang, O. Bloom, M. Zhang, et al., "HMG-1 as a late mediator of endotoxin lethality in mice," Science, vol. 285, no. 5425, pp. 248-251, 1999.

[3] H. Yang, H. Wang, C. J. Czura, and K. J. Tracey, "The cytokine activity of HMGB1," Journal of Leukocyte Biology, vol. 78, no. 1, pp. 1-8, 2005.

[4] U. Andersson, H. Erlandsson-Harris, H. Yang, and K. J. Tracey, "HMGB1 as a DNA-binding cytokine," Journal of Leukocyte Biology, vol. 72, no. 6, pp. 1084-1091, 2002.

[5] E. D. Peltz, E. E. Moore, P. C. Eckels, et al., "HMGB1 is markedly elevated within 6 hours of mechanical trauma in humans," Shock, vol. 32, no. 1, pp. 17-22, 2009.

[6] M. A. D. van Zoelen, H. Yang, S. Florquin, et al., "Role of toll-like receptors 2 and 4, and the receptor for advanced glycation end products in high-mobility group box 1-induced inflammation in vivo," Shock, vol. 31, no. 3, pp. 280-284, 2009.

[7] M. P. Fink, "Bench-to-bedside review: high-mobility group box 1 and critical illness," Critical Care, vol. 11, no. 5, article 229, 2007.

[8] H. Wang, S. Zhu, R. Zhou, W. Li, and A. E. Sama, "Therapeutic potential of HMGB1-targeting agents in sepsis," Expert Reviews in Molecular Medicine, vol. 10, article e32, 2008.

[9] S. Muller, L. Ronfani, and M. E. Bianchi, "Regulated expression and subcellular localization of HMGB1, a chromatin protein with a cytokine function," Journal of Internal Medicine, vol. 255, no. 3, pp. 332-343, 2004.

[10] H. M. Weir, P. J. Kraulis, C. S. Hill, A. R. C. Raine, E. D. Laue, and J. O. Thomas, "Structure of the HMG box motif in the B-domain of HMG1,” EMBO Journal, vol. 12, no. 4, pp. 13111319, 1993.

[11] Q. Wang, M. Zeng, W. Wang, and J. Tang, "The HMGB1 acidic tail regulates HMGB1 DNA binding specificity by a unique mechanism," Biochemical and Biophysical Research Communications, vol. 360, no. 1, pp. 14-19, 2007.

[12] J. Li, R. Kokkola, S. Tabibzadeh, et al., "Structural basis for the proinflammatory cytokine activity of high mobility group box 1," Molecular Medicine, vol. 9, no. 1-2, pp. 37-45, 2003.

[13] H. Yang, M. Ochani, J. Li, et al., "Reversing established sepsis with antagonists of endogenous high-mobility group box 1," Proceedings of the National Academy of Sciences of the United States of America, vol. 101, no. 1, pp. 296-301, 2004.

[14] Q. Gong, J.-F. Xu, H. Yin, S.-F. Liu, L.-H. Duan, and Z.-L. Bian, "Protective effect of antagonist of high-mobility group box 1 on lipopolysaccharide-induced acute lung injury in mice," Scandinavian Journal of Immunology, vol. 69, no. 1, pp. 29-35, 2009.

[15] S. Knapp, S. Muller, G. Digilio, T. Bonaldi, M. E. Bianchi, and G. Musco, "The long acidic tail of high mobility group box 1 (HMGB1) protein forms an extended and flexible structure that interacts with specific residues within and between the HMG boxes," Biochemistry, vol. 43, no. 38, pp. 11992-11997, 2004.

[16] W. Gong, F. T. He, R. F. Li, et al., "Effects of acidic tail on human HMGB1 antibacterial activity," Chinese Journal of Biochemistry and Molecular Biology, vol. 22, no. 7, pp. 524529, 2006.

[17] P. Scaffidi, T. Misteli, and M. E. Bianchi, "Release of chromatin protein HMGB1 by necrotic cells triggers inflammation," Nature, vol. 418, no. 6894, pp. 191-195, 2002.
[18] E. Abraham, J. Arcaroli, A. Carmody, H. Wang, and K. J. Tracey, "HMG-1 as a mediator of acute lung inflammation," Journal of Immunology, vol. 165, no. 6, pp. 2950-2954, 2000.

[19] D.-Y. Chen, L.-M. Liu, S.-J. Liu, M.-Y. Zhu, L. Xu, and T.H. Huang, "Single-chain antibody against human lipocalintype prostaglandin D synthase: construction, expression, purification, and activity assay," Biochemistry, vol. 73, no. 6, pp. 702-710, 2008.

[20] U. Andersson, H. Wang, K. Palmblad, et al., "High mobility group 1 protein (HMG-1) stimulates proinflammatory cytokine synthesis in human monocytes," Journal of Experimental Medicine, vol. 192, no. 4, pp. 565-570, 2000. 

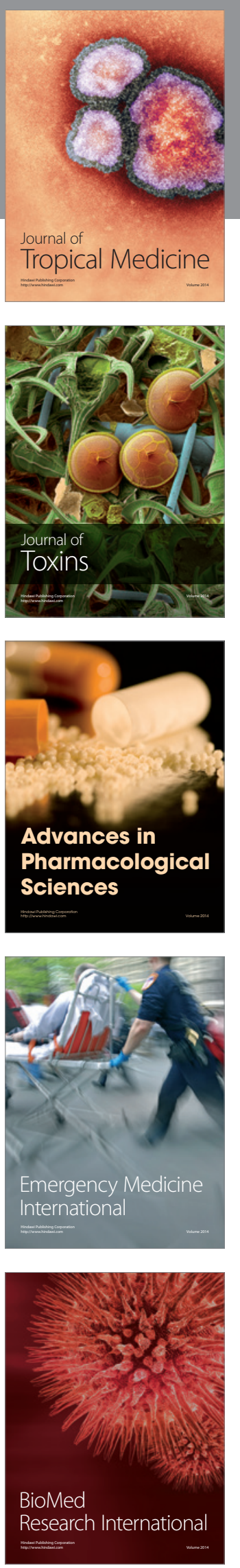
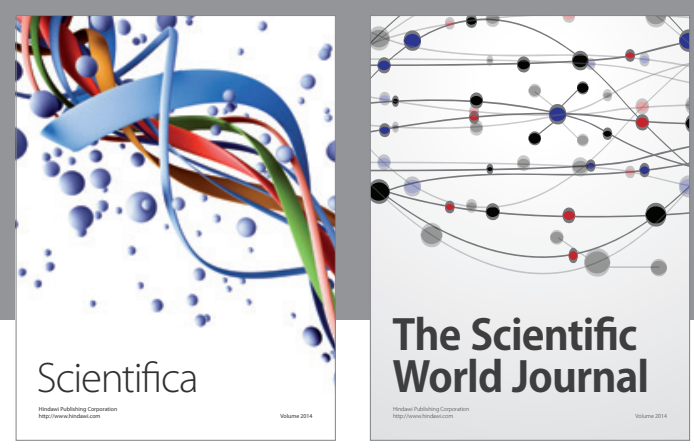

The Scientific World Journal
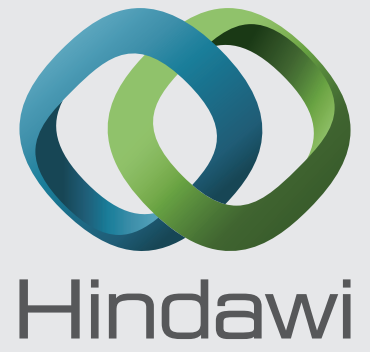

Submit your manuscripts at

http://www.hindawi.com
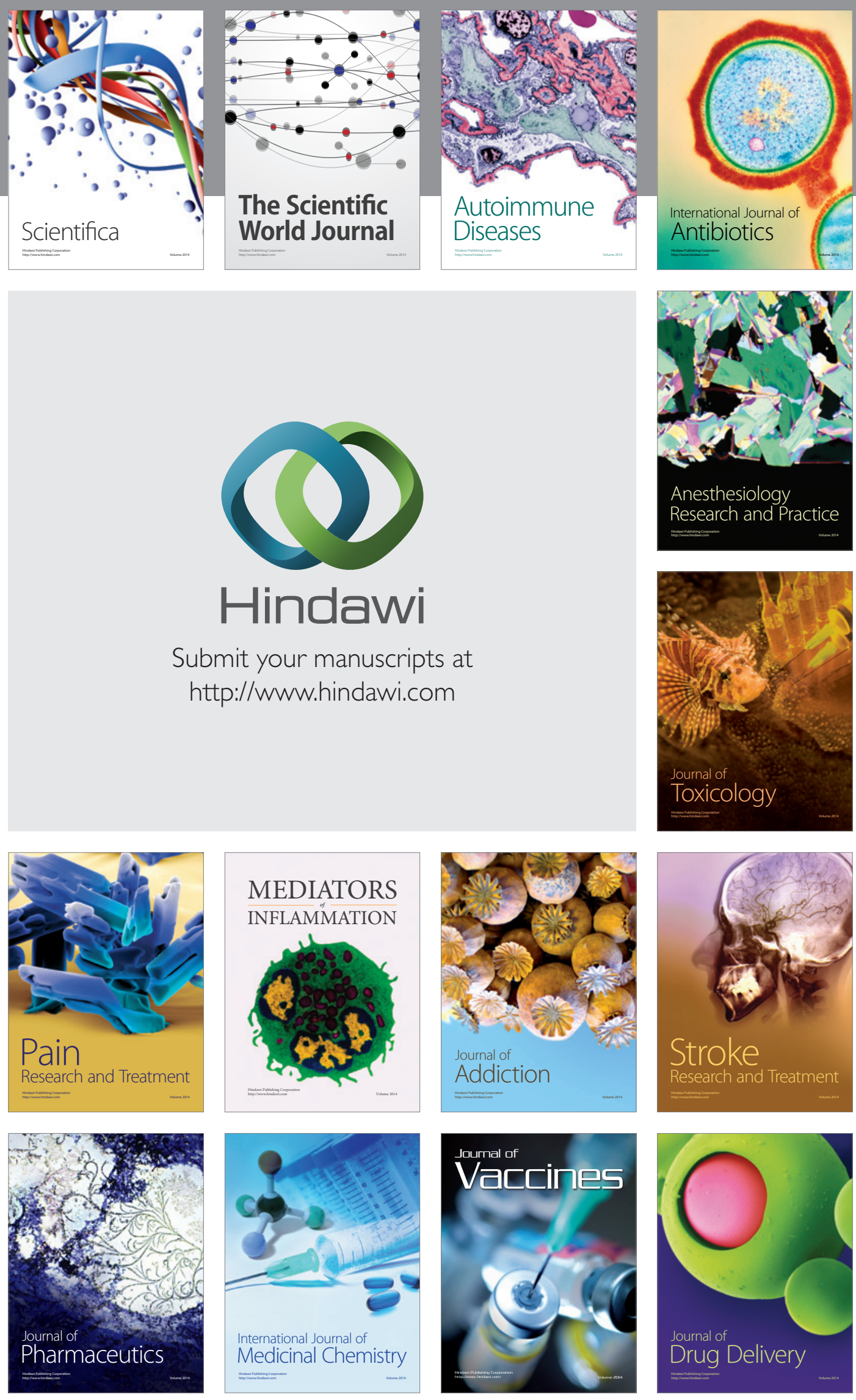